\title{
Propedêutica neurológica do recém-nascido e sua evolução
}

\section{Neurological evaluation and follow-up of the newborn infant}

\author{
José Luiz Dias Gherpelli(1)
}

\begin{abstract}
Gherpelli JLD. Propedêutica neurológica do recém-nascido e sua evolução. Rev Med (São Paulo) 2003 jan.-dez.;82(1-4):22-33.

RESUMO: O autor descreve a propedêutica neurológica do recém-nascido a termo e pré-termo, tecendo considerações sobre as técnicas de exame mais freqüentemente empregadas na prática clínica e as síndromes neurológicas observadas no período neonatal. Posteriormente, descreve os padrões de desenvolvimento observados em crianças normais nos primeiros anos de vida, nas áreas motora, de linguagem, coordenação motora e adaptativa, descrevendo os testes mais comuns utilizados na avaliação das crianças pré-escolares.
\end{abstract}

DESCRITORES: Desempenho psicomotor. Desenvolvimento infantil. Exame neurológico/métodos. Recém-nascido. Prematuro.

\section{INTRODUÇÃO}

As patologias neurológicas do recém-nascido (RN) apresentam uma etiologia bastante variada. Compreendem desde patologias que afetam o embrião, como as malformações do Sistema Nervoso Central (SNC) e as cromossomopatias, passando pelas que comprometem o desenvolvimento do SNC do feto, como as infecções congênitas, patologias placentárias ou maternas, até aquelas que afetam o RN, como as complicações do trabalho de parto, da prematuridade e outras relacionadas com patologias adquiridas durante $\mathrm{o}$ período neonatal: encefalopatia hipóxico-isquêmica, hemorragias intracranianas, meningites e encefalites, convulsões, tocotraumatismos, distúrbios metabólicos e intoxicações.

\footnotetext{
${ }^{(1)}$ Livre Docente em Neurologia Infantil pela FMUSP. Médico do Serviço de Neurologia Infantil da Clínica Neurológica do Hospital das Clínicas da FMUSP. Neurologista Infantil do Hospital Israelita Albert Einstein.

Endereço para correspondência: Hospital Israelita Albert Einstein. Av. Albert Einstein, 627. 13º andar, Conj. 1308. 05651-901 São Paulo, SP. e-mail: jldg@osite.com.br
} 


\section{EXAMENEUROLÓGICODORN}

\section{RN a termo}

O exame neurológico no período neonatal tem os seguintes objetivos: 1. diagnosticar uma disfunção aguda do SNC (p. ex.: diagnosticar o comprometimento do SNC em um RN asfixiado); 2. permitir o acompanhamento evolutivo de uma patologia neurológica estabelecida (p. ex.: acompanhamento de um RN com meningite bacteriana); 3. dar informações que possam ser utilizadas para o prognóstico neurológico a médio e longo prazo (p. ex.: prognóstico de RN pré-termo com hemorragia intracraniana). Esses objetivos nem sempre podem ser totalmente atingidos na totalidade dos casos, pois uma série de funções nervosas superiores relacionadas a processos de linguagem, comportamento e inteligência ainda não são passíveis de avaliação no período neonatal.

A padronização do exame neurológico é fundamental, a fim de que os resultados possam ser confiáveis. Assim, o ambiente em que o exame será realizado deve ser bem iluminado e apresentar uma temperatura compatível com o fato do RN ser examinado despido. O examinador deve realizar o exame no menor tempo possível, evitando movimentos bruscos e manipulação excessiva que desencadeiam o choro e irritabilidade os quais podem prejudicar a interpretação de determinadas manobras e reflexos. O exame deve ser idealmente realizado no intervalo entre as mamadas pois, logo após a alimentação, o RN se encontra sonolento e é difícil mantê-lo desperto e, antes das mamadas, ele freqüentemente chora e se irrita com maior facilidade, o que prejudica a interpretação de alguns testes (p. ex.: o reflexo de sucção geralmente se encontra deprimido após as mamadas e a avaliação do tono muscular não é confiável num RN chorando).

Antes de discutirmos a técnica de avaliação propriamente dita, é essencial que se introduza o conceito dos "estados comportamentais". É comum que o neonatologista examine um RN sem se preocupar se ele está desperto ou dormindo. Para determinados tipos de semiologia, como a pulmonar e a respiratória, é até interessante que a criança esteja dormindo, pois assim consegue-se ouvir melhor as bulhas cardíacas e a ausculta pulmonar. Estados comportamentais são variáveis que identificam comportamentos consistentemente observados num $\mathrm{RN}$ normal e que refletem o status de funcionamento do SNC naquele momento em que são observados. Precht $1^{5}$ definiu cinco estados comportamentais no RN a termo com base na observação de três variáveis: abertura ocular, padrão respiratório e movimentos corpóreos (Tabela 1).

Tabela 1. Estados comportamentais do RN a termo

\begin{tabular}{llllll}
\hline Estado & $\mathbf{1}$ & $\mathbf{2}$ & $\mathbf{3}$ & $\mathbf{4}$ & $\mathbf{5}$ \\
\hline Variável & (sono quieto) & (sono ativo) & (despertar quieto) & (despertar ativo) & (choro) \\
\hline Olhos & Fechados & Fechados & Abertos & Abertos & - \\
Movimentos respiratórios & Regulares & Irregulares & Regulares & Irregulares & choro \\
Movimentos corpóreos & Ausentes & Presentes & Ausentes & Presentes & - \\
\hline
\end{tabular}

Algumas respostas reflexas que integram o exame neurológico do RN mostram uma dependência nítida com certos estados comportamentais $^{6}$ (Tabela 2). Os reflexos proprioceptivos são facilmente obtidos nos estado 1 e 3 , entretanto estão abolidos ou hipoativos no estado 2 . Os reflexos exteroceptivos estão presentes nos estados 2 e 3, mas encontram-se deprimidos no estado 1 . Além disso, o clono do pé, uma resposta normalmente considerada patológica, pode ser encontrado no estado 1 sem que isto tenha um significado patológico. A questão pode a princípio parecer irrelevante, pois os reflexos estão presentes na sua forma habitual no RN desperto. Entretanto, é muito comum que algumas provas do exame neurológico neonatal sejam pesquisadas com a criança dormindo, sem que o examinador se preocupe em observar os estados comportamentais, o que obviamente poderia falsear os resultados. Assim, na dúvida, é melhor que o exame seja realizado com a criança desperta durante todo o transcorrer da avaliação. 
Rev Med (São Paulo) 2003 jan.-dez.;82(1-4):22-33.

Tabela 2. Relação de alguns reflexos com estados comportamentais do RN

\begin{tabular}{|c|c|c|c|}
\hline Reflexos & Estado 1 & Estado 2 & Estado 3 \\
\hline \multicolumn{4}{|l|}{ Proprioceptivos } \\
\hline Patelar & +++ & $+/-$ & ++ \\
\hline Bicipital & +++ & $+/-$ & ++ \\
\hline Clono de Pé & +++ & - & - \\
\hline Moro & +++ & $+/-$ & ++ \\
\hline \multicolumn{4}{|l|}{ Exteroceptivos } \\
\hline Voracidade & - & - & ++ \\
\hline Preensão Palmar & - & + & ++ \\
\hline Preensão Plantar & - & ++ & ++ \\
\hline \multicolumn{4}{|l|}{ Pressão } \\
\hline Babkin & - & + & ++ \\
\hline Palmo-Mentual & - & ++ & +++ \\
\hline \multicolumn{4}{|l|}{ Nociceptivos } \\
\hline Cutâneo-Plantar & ++ & +++ & +++ \\
\hline Cutâneo-Abdominal & ++ & +++ & +++ \\
\hline \multicolumn{4}{|l|}{ Respostas Auditivas } \\
\hline Orientação Auditiva & $+/-$ & ++ & +++ \\
\hline \multicolumn{4}{|l|}{ Respostas Vestibulares } \\
\hline Vestíbulo-Ocular & - & ++ & +++ \\
\hline
\end{tabular}

No sentido de limitar a manipulação excessiva do $\mathrm{RN}$ deve-se procurar examiná-lo segundo um roteiro que limite ao mínimo à quantidade de manipulações e mudanças de decúbito (Tabela 3).

Tabela 3. Roteiro do exame neurológico do RN

\begin{tabular}{llll}
\hline Dorsal Horizontal & Ventral Horizontal & Suspensão Ventral & Suspensão Vertical \\
\hline Postura & Elevação Cefálica & Tono Axial (dorso) & Marcha Reflexa \\
Tono Muscular & Rotação Cefálica & Extensão Cefálica & Apoio Plantar \\
Força Muscular & Reflexo de Gallant & & Endireitamento do Tronco \\
Motilidade espontânea & Reflexo Anal & & Respostas Óculo-Vestibulares \\
Reflexos Arcaicos & Exame da Coluna & & \\
Pares Cranianos & & & \\
Exame do Crânio & & & \\
Sensibilidade Dolorosa & & & \\
Manobra da Tração & & & \\
\hline
\end{tabular}

Assim, inicia-se o exame com a criança despida, em decúbito dorsal horizontal. Nessa posição são observadas as posturas e a motilidade espontânea. O RN apresenta normalmente uma postura assimétrica, com a cabeça lateralizada e os membros em semiflexão, devido à hipertonia fisiológica característica dessa faixa etária. Movimentos de flexão-extensão dos membros, do tipo "pedalagem ou natatórios", são os predominantes. A presença de assimetria evidente na motilidade é sinal de anormalidade. O tono e a força muscular são examinados a seguir, através de manobras de contenção da movimentação ativa e de "rechaço" das extremidades (o examinador promove a extensão passiva da extremidade do RN que é liberada a seguir, observando-se o retorno ao padrão flexor normal), bem como através das medidas dos ângulos das principais articulações dos MMII e MMSS (ângulos pé-perna e poplíteo, nos MMII e ângulo da "janela" e "manobra do cachecol" nos MMSS). A pesquisa dos reflexos miotáticos (patelar, aquileu, adutor, estilo-radial, bicipital e tricipital) e dos reflexos nociceptivos superficiais (cutâneo-plantar e cutâneos-abdominais) é realizada da forma habitual. Todos esses reflexos estão presentes no RN a termo normal. Os seguintes reflexos arcaicos ou primitivos (Tabela 4) podem ser testados nessa posição: preensão palmar e plantar, sucção, voracidade, extensão cruzada, tônicocervical (Magnus de Klein), Babkin e Moro. A testagem 
de alguns pares cranianos pode ser realizada nessa posição: a fixação e seguimento visual; avaliação dos diâmetros e reatividade pupilar à luz; motricidade ocular extrínseca (através da prova dos "olhos de boneca"); mímica facial (principalmente observada durante o choro); cócleopalpebral (piscamento após estímulo sonoro); deglutição, movimentos mastigatórios e linguais (observados durante a sucção). Termina-se essa fase do exame com a manobra de tração, na qual o RN é tracionado pelos MMSS da posição deitada para a sentada, observando-se o grau de sustentação cefálica e o equilíbrio transitório da cabeça em relação ao tronco na posição sentada.

Tabela 4. Reflexos arcaicos ou primitivos

\begin{tabular}{|c|c|c|}
\hline REFLEXO & ESTÍMULO & RESPOSTA \\
\hline Moro & queda cefálica de $30^{\circ}$ & abdução-extensão seguida de adução-flexão de MMSS \\
\hline Preensão palmar & estímulo pressórico na palma da mão & flexão dos dedos da mão \\
\hline Preensão plantar & estímulo pressórico na base dos artelhos & flexão dos artelhos \\
\hline Tônico-cervical & Rotação lateral cefálica & $\begin{array}{l}\text { extensão dos membros ipsolaterais e flexão dos } \\
\text { contralaterais }\end{array}$ \\
\hline Babkin & estímulo pressórico na palma das mãos & protusão dos lábios \\
\hline Marcha & RN em pé, apoiando-se as plantas dos pés no leito & movimentos de marcha dos MMII \\
\hline Sucção & estímulo pressão sobre a língua & movimentos de sucção \\
\hline Voracidade & estímulo tátil na região orbicular & lateralização da boca e cefálica em direção ao estímulo \\
\hline $\begin{array}{l}\text { Apoio Plantar } \\
\text { Gallant }\end{array}$ & $\begin{array}{l}\text { estímulo tátil na planta dos pés } \\
\text { estímulo tátil na pele do dorso, paralelo à coluna }\end{array}$ & movimento de extensão do membro inferior \\
\hline Extensão Cruzada & $\begin{array}{l}\text { vertebral, de cada lado } \\
\text { estímulo tátil na planta do pé }\end{array}$ & $\begin{array}{l}\text { encurvamento do dorso se afastando do estímulo } \\
\text { flexão, seguida de extensão e adução do membro } \\
\text { inferior contralateral }\end{array}$ \\
\hline
\end{tabular}

A seguir coloca-se o RN em decúbito ventral horizontal, observando a elevação transitória e rotação lateral da cabeça em relação à superfície do local do exame. A pesquisa do reflexo de Gallant ou de encurvamento do tronco pode ser feita nessa posição. O reflexo anal (contração do ânus à estimulação perineal) deve ser pesquisado a seguir. Sua ausência, como em casos de mielomeningocele, aponta para um comprometimento das porções sacrais da medula espinal.

A seguir, eleva-se o $\mathrm{RN}$ do leito em decúbito ventral, sustentado pela mão do examinador, observando-se a curvatura do dorso e a posição da cabeça em relação ao tronco.

Com o RN suspenso pelas axilas em posição vertical, o examinador executa um movimento de rotação de $360^{\circ}$ de cada lado, observando as respostas óculo-vestibulares. Os reflexos de apoio plantar e a marcha reflexa são testados a seguir.

A pesquisa da sensibilidade somática geral do $\mathrm{RN}$ é tarefa difícil pois, em geral, apenas é possível objetivar as respostas desencadeadas por estímulos dolorosos, os quais freqüentemente desencadeiam choro e irritabilidade na criança, prejudicando o restante do exame. Deve-se testála no final da avaliação. Um estímulo doloroso é aplicado sobre a região a ser examinada (objeto pontiagudo não perfurante) e a resposta do tipo retirada ou choro é observada.

O exame do crânio, com a medida do perímetro cefálico (PC), palpação dos ossos do crânio, suturas e fontanelas é parte importante da avaliação. A tensão da fontanela bregmática, medida através da palpação da mesma, reflete a pressão intracraniana e deve ser realizada com o RN elevado de $30^{\circ}$ em relação ao leito, sem que a criança esteja chorando ou realizando algum tipo de esforço físico; nessa posição a fontanela deve estar plana. A medida do PC deve ser confrontada com tabelas de normatização respeitando-se a IG. Macrocefalia ou macrocrania são os termos utilizados para definir um PC acima do percentil 98 e, microcefalia para aqueles abaixo do percentil 2, para uma dada IG. As macrocefalias são encontradas em casos de hidrocefalia de qualquer etiologia, enquanto que as microcefalias são observadas em algumas malformações do SNC e certas infecções congênitas, como a citomegalovirose e a rubéola.

O exame da coluna vertebral deve ser feito em toda sua extensão tomando-se particular atenção para o encontro de tumorações, depressões, deformidades e anormalidades cutâneas (presença de angiomas ou tufos de pelos) que, em geral, denotam patologias da região, como as meningomieloceles, diastematomielias, lipomas e seios dermóides.

\section{RN pré-termo}

A avaliação neurológica do RN pré-termo deve levar em consideração que estamos lidando com um SNC numa fase de desenvolvimento diferente daquele do RN a termo. Atualmente, com a melhora dos cuidados intensivos 
neonatais, RN com 26 semanas de idade gestacional (IG) estão sobrevivendo. Temos, portanto, um período de até três meses durante os quais o SNC dessas crianças sofrerá uma série de modificações sob condições freqüentemente adversas. Processos como a migração celular, mielinização, arborização dendrítica e ramificação axonal estão em curso e levam a uma mudança nos padrões de comportamento observados nesses RN ao longo desse período.

Com base nisso, podemos tirar duas conclusões: 1 . o exame neurológico do RN pré-termo deve respeitar o caráter evolutivo do desenvolvimento do seu sistema nervoso; e 2. a sistematização do exame neurológico do RN a termo não pode, simplesmente, ser transferida para o pré-termo. Além disso, os estados comportamentais do RN pré-termo não estão definitivamente estabelecidos até a $36^{\mathrm{a}}$ semana de IG, portanto isto faz com que as avaliações neurológicas dos prematuros sejam menos fidedignas em relação a alguns aspectos do exame neurológico (reflexos proprioceptivos, exteroceptivos e respostas a estímulos auditivos) já que não é possível predizer qual será a resposta encontrada para alguns testes em determinado momento.

Estudos da escola francesa demonstraram na década de 50 que a evolução neurológica do RN pré-termo é semelhante para uma mesma $\mathrm{IG}^{7}$. O caráter evolutivo do exame fez com que ele fosse dividido em "idades-chave" $\mathrm{e}$ a técnica é baseada na avaliação de 3 itens do comportamento como mostra a Tabela 4 - 1. "tono passivo" (extensibilidade e passividade das articulações); 2. "tono ativo" (movimentação espontânea ou desencadeada por estímulos externos); e 3. reflexos primitivos (Moro, marcha, voracidade, preensão palmar, extensão cruzada e marcha).

\section{RN com 28 semanas de IG}

1. Tono Ativo - a motilidade espontânea se caracteriza por movimentos lentos, localizados ou generalizados, entremeados por movimentos mais abruptos e rápidos. Essa movimentação tende a ocorrer em "surtos" agrupados, seguidos por períodos de inatividade por vezes prolongados. A motilidade tende a ser maior em MMII quando comparada aos MMSS. Tremores finos e de pequena amplitude e abalos musculares tipo "startle" são freqüentes. A resposta de endireitamento da cabeça (RN na posição sentada com a cabeça pendendo sobre o tórax; resposta: extensão cefálica) começa a se esboçar, necessitando entretanto de um estímulo peri-orbicular. O mento não ultrapassa o nível do acrômio, em decúbito dorsal, e a face está em completo contato com o leito. A reação de endireitamento dos MMII, avaliada através da pesquisa do reflexo de apoio plantar, mostra apenas uma extensão transitória e efêmera.

2. Tono Passivo - encontra-se uma hipotonia global importante, com postura extensora das extremidades. $\mathrm{O}$ ângulo poplíteo é de $180^{\circ}$ e o pé-perna em torno de $40^{\circ}$.

3. Reflexos: a) voracidade: esboço de movimentos de lateralização da cabeça; b) preensão palmar: observase a resposta limitada à extensão dos dedos; 3) Moro: a resposta observada é a abertura das mãos; 4) extensão cruzada: o reflexo é pesquisado através da estimulação tátil da planta do pé do membro inferior extendido e a resposta se divide em três fases: flexão, abdução e extensão-adução do membro inferior contralateral ao estímulo. Nesta IG não se observa resposta alguma.

\section{RN com 30 semanas de IG}

1. Tono Ativo - os movimentos espontâneos são mais rápidos e freqüentes e o endireitamento da cabeça e dos MMII é mais facilmente observado.

2. Tono Passivo - a hipotonia muscular continua intensa. O ângulo poplíteo é menor $\left(150^{\circ}\right)$.

3. Reflexos Primitivos - a) Voracidade: observa-se a resposta nas 4 direções; b) Preensão palmar: mais facilmente obtida; c) Moro: abertura das mãos; d) Extensão cruzada: apenas a resposta flexora.

\section{RN com 32 semanas de IG}

1. Tono Ativo - nota-se o esboço do endireitamento do tronco, após uma extensão nítida e prolongada dos MMII. A qualidade da motilidade espontânea é característica desta IG, com elevações dos MMII e dos quadris além de movimentos de torção do tronco, os quais permitem a mudança de decúbito do RN.

2. Tono Passivo - o ângulo poplíteo está mais fechado $130^{\circ}$ e o balanço passivo dos MMII já denota uma certa resistência. Ao se executar a manobra calcanharorelha, apesar de fácil realização, já se encontra uma certa resistência ao movimento.

3. Reflexos Primitivos: a) voracidade: completo, com a participação da língua, podendo desencadear movimentos de sucção; b) preensão palmar: sólida, conseguindo-se uma ligeira elevação do RN do leito, com a tração dos MMSS; c) Moro: resposta em abdução, extensão dos MMSS, além da abertura das mãos; d) extensão cruzada: aparece a abdução, após o movimento de flexão.

\section{RN com 35 semanas de IG}

1. Tono Ativo - a atitude em "batráquio" (flexão e abdução dos MMII e extensão dos MMSS), característica desta IG pode ser observada. O endireitamento da cabeça é observado à manobra do apoio-plantar e a cabeça já não fica totalmente apoiada sobre o leito, ficando o mento acima da linha acromial.

2. Tono Passivo - o ângulo poplíteo é de $90^{\circ}$ (semelhante ao RN a termo).

3. Reflexos Primitivos: a) voracidade: completo; b) preensão palmar: sólida, com difusão do padrão flexor para os músculos do antebraço; c) Moro: padrão de abduçãoextensão semelhante ao RN a termo, porém sem a fase de 
flexão-adução; d) extensão cruzada: além da flexão inicial, agora notamos a resposta em abdução nítida; e) marcha: começa a ser obtida, mas sem consistência e continuidade.

\section{RN com 37 semanas de IG}

1. Tono Ativo - nota-se a atitude flexora, tanto em MMII, quanto em MMSS, menos intensa que a observada nos RN a termo. Essa hipertonia fisiológica leva a uma certa limitação da motilidade espontânea, a qual fica um tanto reduzida, na quantidade e amplitude dos movimentos. Já é possível observar-se a reação de endireitamento global, isto é, o endireitamento dos MMII, seguido do tronco e, finalmente, do segmento cefálico. A posição do mento está agora bem acima do nível acromial e os movimentos de lateralização ativa da cabeça são freqüentes.

2. Tono Passivo - o ângulo poplíteo permanece em $90^{\circ}$ e o pé-perna, em torno de $10^{\circ}$. A extensibilidade articular é semelhante ao RN a termo.

3. Reflexos Primitivos - a) voracidade: completo; b) Preensão palmar: sólida, com irradiação nítida para as porções mais proximais dos MMSS; c) Moro: a fase de adução e flexão é agora observada; d) extensão cruzada: ocorre o aparecimento da fase extensora que domina todas as outras; e) marcha: presente de forma completa.

Pode-se dizer que a evolução ontogenética do tono muscular dos prematuros segue uma direção caudocefálica, enquanto que a dos reflexos segue um padrão inverso. Diversos aspectos relacionados à avaliação neurológica do tono muscular do RN pré-termo são utilizados nos exames clínicos realizados em berçário com o objetivo de estimar a IG dessas crianças.

\section{Síndromes neurológicas neonatais}

As anormalidades do exame neurológico do RN são comumente agrupadas na forma de síndromes neurológicas: hemisíndrome, hiperexcitabilidade, apática, hipertônica e hipotônica ${ }^{8}$ (Tabela 5).

\section{Tabela 5. Síndromes neurológicas do período neonatal}

Hemisíndrome

Síndrome da hiperexcitabilidade

Síndrome apática

Síndrome hipertônica

Síndrome hipotônica

1. Hemisíndrome - se caracteriza pelo encontro de assimetrias ao exame neurológico, como uma hemiparesia, monoparesia ou assimetrias na mímica facial. As hemiparesias, propriamente ditas são raramente observadas no período neonatal e, em geral, denotam a existência de lesões maciças acometendo um dos hemisférios cerebrais, como aquelas determinadas pela compressão causada por um hematoma subdural, ou secundárias a um acidente vascular cerebral isquêmico (trombose arterial ou venosa) ou hemorrágico (hematoma parenquimatoso). Dentre as monoparesias temos a clássica paralisia braquial por tocotraumatismo. A paralisia do nervo facial secundária a tocotraumatismo é o exemplo mais freqüente da assimetria facial não devendo ser confundido com a agenesia do músculo depressor do ângulo da boca, aonde há uma assimetria restrita à depressão do ângulo da boca sem comprometimento do restante da musculatura facial. O prognóstico depende da severidade da lesão de base.

2. Hiperexcitabilidade - caracterizada pela presença de tremores grosseiros, de baixa freqüência e alta amplitude, associados a uma hiperreflexia miotática e presença de clono de pé. O reflexo de Moro tem seu limiar diminuído, sendo observado mesmo com mínimas manipulações do RN. A síndrome da hiperexcitabilidade foi associada a distúrbios de natureza metabólica (hipocalcemia, hipomagnesemia e hipoglicemia), encefalopatia hipóxico-isquêmica leve, RCIU, RN de mães diabéticas e hemorragias subaracnóideas ${ }^{3}$. A evolução, em geral, é favorável, com remissão espontânea ainda no primeiro mês de vida, e o prognóstico, na maioria dos casos, é bom.

3. Síndrome Apática - é caracterizada essencialmente por sinais que denotem um estado de torpor ou coma. A motilidade espontânea está bastante reduzida ou ausente. Há uma abolição dos reflexos arcaicos e o tono muscular encontra-se alterado, ou para uma hipotonia (mais freqüente), ou hipertonia. Na dependência do grau de comprometimento do SNC, podemos encontrar sinais de comprometimento do tronco cerebral (anormalidades pupilares, estrabismos, alterações respiratórias). É observada em casos de encefalopatia hipóxico-isquêmica severa ou em casos de hemorragias intracranianas maciças, no RN pré-termo. Sua evolução, em geral, é lenta com regressão progressiva do quadro e o prognóstico é reservado na maioria dos casos.

4. Síndrome Hipertônica - se caracteriza pelo aumento do tono muscular, acompanhado de uma diminuição da motilidade espontânea, podendo ocorrer uma hiperreflexia miotática global. É observada na evolução de alguns casos de encefalopatia hipóxico-isquêmica moderadas ou severas, principalmente, após a primeira semana de vida, e em RN pré-termos com hemorragias periintraventriculares. Podem ser observadas em casos de hiperekplexia ou de "stiff-baby syndrome", patologias raras.

5. Síndrome Hipotônica - a hipotonia muscular em graus variados caracteriza essa síndrome neurológica neonatal, que pode vir acompanhada de uma hipo ou arreflexia miotática. Podem estar associadas a distúrbios de natureza metabólica (hipo ou hipercalemia, hipermagnesemia, hipoglicemia). Quando associadas à síndrome apática, denotam um comprometimento do SNC (p. ex.: encefalopatias hipóxico-isquêmica, hemorragias intracranianas, erros inatos do metabolismo, infecções congênitas, etc.). Entretanto, quando isoladas apontam 
para lesão do corno anterior da medula espinal (amiotrofia espinal de Werdnig-Hoffmann), nervos (neuropatias traumáticas), junção neuro-muscular (miastenia gravis forma neonatal), ou músculo (miopatias congênitas). Algumas formas leves de hipotonia do RN são observadas em RN PIG, ou RN pré-termos, desaparecendo espontaneamente nos primeiros meses de vida e, possivelmente, são secundárias à hipotrofia muscular encontrada nesses RN, sem representar uma patologia neurológica propriamente dita.

\section{DESENVOLVIMENTO NEUROPSICOMOTOR DA CRIANÇA}

As várias etapas do desenvolvimento neuropsicomotor (DNPM) da criança refletem o desenvolvimento de seu sistema nervoso central (SNC), sendo, portanto, importantes marcadores semiológicos de sua integridade.

O SNC da criança é um sistema em constante evolução e transformação. Desde a vida intrauterina, ele se desenvolve e amadurece e esse desenvolvimento se processa até a idade adulta através de processos de maturação e transformação. Essas modificações são a resultante da interação entre forças intrínsecas, de natureza genética, e extrínsecas, que dependem do meio ambiente. $\mathrm{O}$ resultado final da interação desses fatores determina o DNPM da criança. Patologias que comprometem o desenvolvimento do SNC irão resultar em modificações desse processo e freqüentemente se traduzem em atraso, regressão, ou interrupção do DNPM da criança.

A observação dos vários tipos de comportamentos do ser humano, quer sejam espontâneos, quer sejam em resposta a estímulos ambientais, dirigidos ou não, são utilizados na avaliação semiológica da competência e integridade do SNC.

A ultra-sonografia permitiu a observação de movimentos espontâneos a partir da $8^{\mathrm{a}}$ semana de formação do embrião humano e, com 15 semanas, já é possível a distinção de 15 diferentes tipos de movimentos no feto ${ }^{2}$ (Tabela 6). Os estados comportamentais observados em recém-nascidos $(\mathrm{RN})$ podem ser identificados intra-útero na mesma idade concepcional em que são observados em bebês nascidos prematuramente.

Tabela 6. Tipos de movimentos observados em embriões e fetos humanos através da ultra-sonografia

\begin{tabular}{lc}
\hline Movimento & Época do aparecimento (em semanas) \\
\hline "Startle" & 8 \\
Movimento corpóreo generalizado & $8-9$ \\
Soluços & $8-10$ \\
Movimento isolado de MMSS & $9-10$ \\
Movimento isolado de MMII & $9-12$ \\
Retroflexão da cabeça & $9-12$ \\
Rotação da cabeça & $10-12$ \\
Contato mão/face & $10-12$ \\
Movimentos respiratórios & $10-12$ \\
Abertura da boca & $10-12$ \\
Espreguiçar & $10-15$ \\
Anteflexão da cabeça & $12-14$ \\
Sucção/Deglutição & $12-15$ \\
\hline
\end{tabular}

O nascimento permite que as observações sejam realizadas através do exame clínico direto do $\mathrm{RN}$, além da realização de exames complementares de neuroimagem, neurofisiológicos e outros que auxiliam no diagnóstico de situações de risco de comprometimento neurológico.

A partir do período neonatal, as avaliações devem sempre levar em conta a idade da criança, pois o SNC se desenvolve durante toda a infância e esse desenvolvimento se traduz em modificações no comportamento que são o reflexo da interação entre o organismo e o meio ambiente.

As avaliações do DNPM devem sempre incluir uma história clínica detalhada dos antecedentes pré, peri e pósnatais que possam interferir com a integridade física, neurológica e psicológica da criança. O parto prematuro é um dado particularmente importante pois além das intercorrências clínicas a que estas crianças estão sujeitas no período neonatal, que são fatores de risco para a integridade do SNC, existem estudos que sugerem que a idade concepcional (idade cronológica + idade gestacional) e não a cronológica é que deve ser utilizada para a avaliação correta do DNPM, principalmente, durante o $1^{\circ}$ ano de vida, eventualmente até o final do $2^{\circ}$ ano.

A existência de anormalidades ao exame físico geral é um fato importante, pois pode sugerir a presença de processos patológicos que indicam possíveis etiologias para anormalidades observadas no DNPM. Assim, a presença de dismorfismos faciais ou corpóreos sugere síndromes malformativas, que podem apresentar natureza 
cromossômica ou gênica. A presença de desnutrição grave em idade precoce indica a presença de fatores de risco de natureza ambiental os quais podem interferir com o DNPM e levar a problemas neurológicos em longo prazo, principalmente na área cognitiva.

O exame neurológico é importante na avaliação do DNPM, pois a presença ou não de anormalidades neurológicas definidas é essencial para o diagnóstico diferencial de anormalidades encontradas nos testes neuropsicológicos. O caráter evolutivo das avaliações deve ser levado em consideração e, nesse sentido, existem inúmeras avaliações na literatura que permitem a adequação das provas semiológicas do exame neurológico tradicionalmente realizado em adultos à idade da criança. Muitas delas incluem casuística própria que corroboram achados observados em escalas de desenvolvimento que tiveram origem na área psicológica e que foram posteriormente incluídas nas avaliações neurológicas evolutivas.

Um simples padrão de comportamento, como a habilidade de tocar um objeto com o dedo indicador, pode ter um alto nível de importância diagnóstica. Entretanto, o organismo humano é um sistema complicado, portanto o diagnóstico do desenvolvimento requer a avaliação da qualidade e integração de várias áreas do comportamento, cada uma delas representando um aspecto diferente do crescimento. De acordo com Gesell ${ }^{4}$, existem cinco áreas que devem ser avaliadas: (1) adaptativo; (2) motor grosseiro; (3) motor fino; (4) linguagem; e (5) pessoal-social (Tabela 7).

Tabela 7. Etapas do desenvolvimento infantil segundo Gesell

\begin{tabular}{|c|c|c|c|c|c|}
\hline Idade & Adaptativo & Motor Grosseiro & Motor Fino & Linguagem & Pesssoal - Social \\
\hline 4 semanas & $\begin{array}{l}\text { Seguimento restrito } \\
\text { do olhar }\end{array}$ & $\begin{array}{l}\text { Reflexo tônico- } \\
\text { cervical }\end{array}$ & Punhos fechados & $3 / 4$ & $\begin{array}{l}\text { Olha para a face do } \\
\text { examinador }\end{array}$ \\
\hline 16 semanas & $\begin{array}{l}\text { Olha para chocalho } \\
\text { na mão }\end{array}$ & Postura simétrica & $\begin{array}{l}\text { Mãos abertas; } \\
\text { arranha e agarra }\end{array}$ & $\begin{array}{l}\text { Sorri; } \\
\text { vocaliza socialmente }\end{array}$ & $\begin{array}{l}\text { Brinca com as mãos; } \\
\text { reconhece a mamadeira }\end{array}$ \\
\hline 28 semanas & $\begin{array}{l}\text { Transfere o cubo } \\
\text { de mão }\end{array}$ & $\begin{array}{l}\text { Senta; projeta-se para } \\
\text { frente apoiando nas } \\
\text { mãos; sustenta peso } \\
\text { com MMII }\end{array}$ & $\begin{array}{l}\text { Agarra o cubo com } \\
\text { as mãos; tenta pegar } \\
\text { objetos pequenos }\end{array}$ & $\begin{array}{l}\text { Vocaliza para } \\
\text { brinquedos; emite } \\
\text { sons consonantais }\end{array}$ & $\begin{array}{l}\text { Brinca com os pés; } \\
\text { Toca na imagem no espelho }\end{array}$ \\
\hline 40 semanas & $\begin{array}{l}\text { Segura mamadeira; } \\
\text { segura objetos } \\
\text { pequenos }\end{array}$ & $\begin{array}{l}\text { Senta-se sem ajuda; } \\
\text { engatinha; fica de pé }\end{array}$ & $\begin{array}{l}\text { Solta objetos; } \\
\text { aponta com o dedo } \\
\text { em direção a objeto }\end{array}$ & $\begin{array}{l}\text { Palavra-frase; } \\
\text { imita sons da fala }\end{array}$ & $\begin{array}{l}\text { Brinca de jogos simples de } \\
\text { berçário; come biscoito com } \\
\text { as mãos }\end{array}$ \\
\hline 52 semanas & $\begin{array}{l}\text { Coloca cubo dentro } \\
\text { do copo; tenta torre } \\
\text { com } 2 \text { cubos }\end{array}$ & $\begin{array}{l}\text { Anda com ajuda; } \\
\text { dá alguns passos } \\
\text { sem apoio }\end{array}$ & Preensão em pinça & $\begin{array}{l}\text { Fala } 2-3 \text { palavras; } \\
\text { reconhece objeto } \\
\text { pelo nome }\end{array}$ & $\begin{array}{l}\text { Coopera no vestir-se; brinca } \\
\text { com a bola }\end{array}$ \\
\hline 18 meses & $\begin{array}{l}\text { Retira pequeno } \\
\text { objeto do copo; } \\
\text { rabisca } \\
\text { espontaneamente }\end{array}$ & $\begin{array}{l}\text { Anda com equilíbrio; } \\
\text { agacha-se }\end{array}$ & $\begin{array}{l}\text { Torre de } 3 \text { cubos; } \\
\text { folheia } 2-3 \text { páginas } \\
\text { de livro de uma } \\
\text { só vez }\end{array}$ & $\begin{array}{l}\text { Jargões; reconhece } \\
\text { figuras }\end{array}$ & $\begin{array}{l}\text { Usa a colher derramando; } \\
\text { puxa o brinquedo andando }\end{array}$ \\
\hline 24 meses & $\begin{array}{l}\text { Constrói torre com } \\
6 \text { cubos; imita círculo } \\
\text { com lápis }\end{array}$ & $\begin{array}{l}\text { Corre com equilíbrio; } \\
\text { chuta bola }\end{array}$ & $\begin{array}{l}\text { Torre com } 6 \text { cubos; } \\
\text { folheia páginas } 1 \\
\text { por vez }\end{array}$ & $\begin{array}{l}\text { Usa frases; } \\
\text { compreende ordens } \\
\text { simples diretas }\end{array}$ & $\begin{array}{l}\text { Coloca partes simples } \\
\text { da vestimenta; } \\
\text { brinca com bonecos }\end{array}$ \\
\hline 36 meses & $\begin{array}{l}\text { Imita ponte com } 3 \\
\text { cubos; copia círculo }\end{array}$ & $\begin{array}{l}\text { Fica num pé só; } \\
\text { pula }\end{array}$ & $\begin{array}{l}\text { Torre com } 10 \text { cubos: } \\
\text { segura o lápis de } \\
\text { forma adequada }\end{array}$ & $\begin{array}{l}\text { Fala formando } \\
\text { sentenças; responde } \\
\text { a questões simples }\end{array}$ & $\begin{array}{l}\text { Usa a colher adequadamente; } \\
\text { coloca sapatos; aguarda a vez }\end{array}$ \\
\hline 48 meses & $\begin{array}{l}\text { Imita portão com } \\
5 \text { cubos; copia } \\
\text { linhas cruzadas }\end{array}$ & $\begin{array}{l}\text { Pula num pé só; } \\
\text { pulo amplo }\end{array}$ & Traços entre linhas & $\begin{array}{l}\text { Usa conjunções; } \\
\text { compreende } \\
\text { preposições }\end{array}$ & $\begin{array}{l}\text { Lava e enxuga a face; } \\
\text { brinca de forma interativa }\end{array}$ \\
\hline 60 meses & $\begin{array}{l}\text { Conta } 10 \text { objetos; } \\
\text { copia triângulo }\end{array}$ & $\begin{array}{l}\text { Pula no pé só } \\
\text { alternadamente }\end{array}$ & $3 / 4$ & $\begin{array}{l}\text { Fala sem dislalias; } \\
\text { pergunta "por que?" }\end{array}$ & $\begin{array}{l}\text { Veste-se sem auxílio; pergunta } \\
\text { o significado das palavras }\end{array}$ \\
\hline
\end{tabular}




\section{COMPORTAMENTO ADAPTATIVO}

Trata da organização dos estímulos, a percepção das relações, a capacidade analítica e de síntese. Incluídos neste item estão os ajustes sensório-motores a objetos e situações, coordenação visuo-motora, habilidades práxicas e gnósticas, e a capacidade de adaptação na presença de problemas simples. O comportamento adaptativo é o primórdio daquilo que se convenciona chamar de "inteligência", que envolve a capacidade de utilizar a experiência prévia na solução de novos problemas.

\section{COMPORTAMENTO MOTOR GROSSEIRO}

Inclui as reações posturais, o controle cefálico, capacidade de sentar, engatinhar, ficar de pé e andar.

\section{COMPORTAMENTOMOTOR FINO}

Consiste na capacidade de utilizar as mãos e dedos na preensão e manipulação de objetos. As habilidades motoras da criança constituem um ponto de partida natural para a avaliação de sua maturidade, entretanto, freqüentemente, elas são os únicos parâmetros efetivamente avaliados. Os comportamentos motor e adaptativo estão intimamente inter-relacionados, mas eles podem e devem ser separados na prática diagnóstica.

\section{LINGUAGEM}

O termo é utilizado de forma ampla nas avaliações de modo a incluir todas as formas de comunicação audível e visível, seja uma expressão facial, gesto, alteração postural, vocalização, palavras, frases ou sentenças. O comportamento de linguagem inclui a mímica e a compreensão da comunicação de outros. As fases préverbais são preparatórias para a verbal. Vocalizações inarticuladas e articuladas precedem as palavras, que são posteriormente aprendidas e reforçadas pelo meio ambiente.

\section{COMPORTAMENTO PESSOAL-SOCIAL}

Refere-se às reações da criança ao meio cultural em que vive. Estas reações apresentam natureza tão multifacetada, variada e dependentes do meio ambiente que podem parecer estar além da capacidade de serem avaliadas pelo diagnóstico do desenvolvimento entretanto, assim como os comportamento das outras áreas, seus padrões de desenvolvimento são determinados por fatores intrínsecos do desenvolvimento. O controle dos esfíncteres, por exemplo, é dependente de fatores culturais e sociais, mas a capacidade de obtê-los depende da maturidade neurológica da criança. Isto se aplica para outras habilidades e atitudes tais como, alimentação, atividade lúdica, asseio, cooperação e respostas às convenções e treinamentos sociais. Mesmo que estes comportamentos estejam sujeitos a variações dependentes do meio social e individuais, elas apresentam limites que podem ter implicações diagnósticas.

Essas áreas do comportamento compõem a base do repertório comportamental da criança, mas é muito importante avaliar a forma pela qual ela apresenta tais comportamentos. Os sistemas sensoriais, como a visão, audição e tato, estão intactos? Se há um comprometimento motor ou sensorial, a criança foi capaz de desenvolver caminhos alternativos para expressar sua compreensão do meio ambiente? Quão organizadas e integradas são suas respostas, sua atenção e capacidade discriminativa? Suas reações emocionais são estáveis e apropriadas para a sua idade e a situação do teste? Qual é o seu nível de frustração e tolerância? As observações comportamentais compreendem aspectos quantitativos e qualitativos que tornam sua interpretação sujeita a erros devidos á falta de atenção para determinados aspectos que não fazem parte da avaliação propriamente dita, mas que podem interferir na interpretação dos resultados.

Atualmente, várias escalas de desenvolvimento são utilizadas na avaliação do DNPM das crianças, todas elas derivadas da escala de Gesell com pequenas variações entre si. Essas escalas foram criadas a partir de estudos que procuraram identificar os padrões normais de desenvolvimento baseados em amostras populacionais nas várias áreas do comportamento: motor grosseiro, motor adaptativo fino, linguagem e pessoal-social. $\mathrm{O}$ diagnóstico de um distúrbio do desenvolvimento não significa necessariamente que haja uma patologia neurológica subjacente, mas indica que existe um desvio da normalidade que merece, ou uma investigação específica, ou um seguimento mais detalhado, a fim de que se estabeleça se ele é secundário a patologia neurológica, variação da normalidade, ou conseqüência de problemas ambientais.

Uma das escalas de desenvolvimento mais utilizada em estudos científicos é o teste de "screening" do desenvolvimento de Denver ${ }^{1}$. A vantagem dessa escala é que ela é de fácil aplicação, não necessita de treinamento especializado, ou de material sofisticado para a sua aplicação e pode ser facilmente aplicada por pessoal da área de saúde qualificado.

O Teste de Screening do Desenvolvimento de Denver (Tabela 8) não é um teste de inteligência. Ele se destina ao uso, na prática clínica, como um instrumento de seleção ("screening"). Ele possibilita ao examinador determinar se o desenvolvimento de uma criança em particular está dentro da faixa da normalidade. O teste não permite a realização de um diagnóstico; seu propósito é o de alertar o examinador quanto à presença de um distúrbio no desenvolvimento que pode eventualmente necessitar uma investigação específica. 
Tabela 8. Teste de "Screening" do Desenvolvimento de Denver

\begin{tabular}{|c|c|c|c|c|}
\hline \multirow{2}{*}{$\begin{array}{l}\text { Item } \\
\text { A. Motor grosseiro }\end{array}$} & \multicolumn{4}{|c|}{ Percentil } \\
\hline & $25 \%$ & $\mathbf{5 0 \%}$ & $75 \%$ & $90 \%$ \\
\hline Prono, eleva cabeça. & & & & $0,7 \mathrm{~m}$ \\
\hline Prono, eleva cabeça à $45^{\circ}$. & & & 1,9 & $2,6 \mathrm{~m}$ \\
\hline Prono, eleva cabeça a $90^{\circ}$ & 1,3 & 2,2 & 2,6 & $3,2 \mathrm{~m}$ \\
\hline Sentado, sustenta a cabeça. & 1,5 & 2,9 & 3,6 & $4,2 \mathrm{~m}$ \\
\hline Prono, eleva o tronco com apoio MMSS. & 2,0 & 3,0 & 3,5 & $4,3 \mathrm{~m}$ \\
\hline Rola na cama. & 2,3 & 2,8 & 3,8 & $4,7 \mathrm{~m}$ \\
\hline Sustenta peso MMII. & 3,4 & 4,2 & 5,0 & $6,3 \mathrm{~m}$ \\
\hline Puxado para sentar, sem queda cabeça. & 3,0 & 4,2 & 5,2 & $7,7 \mathrm{~m}$ \\
\hline Senta sem apoio. & 4,8 & 5,5 & 6,5 & $7,8 \mathrm{~m}$ \\
\hline Fica de pé com apoio. & 5,0 & 5,8 & 8,5 & $10,0 \mathrm{~m}$ \\
\hline Puxa para ficar de pé. & 6,0 & 7,6 & 9,5 & $10,0 \mathrm{~m}$ \\
\hline Senta-se sozinho. & 6,1 & 7,6 & 9,3 & $11,0 \mathrm{~m}$ \\
\hline Anda segurando nos móveis. & 7,3 & 9,2 & 10,2 & $12,7 \mathrm{~m}$ \\
\hline Fica de pé, momentaneamente. & 9,1 & 9,8 & 12,1 & $13,0 \mathrm{~m}$ \\
\hline Mantém-se bem de pé. & 9,8 & 11,5 & 13,2 & $13,9 \mathrm{~m}$ \\
\hline Oscila e equilibra-se. & 10,4 & 11,6 & 13,2 & $14,3 \mathrm{~m}$ \\
\hline Anda bem sem apoio. & 11,3 & 12,1 & 13,5 & $14,3 \mathrm{~m}$ \\
\hline Anda para trás. & 12,4 & 14,3 & 18,2 & $21,5 \mathrm{~m}$ \\
\hline Sobe degraus. & 14,0 & 17,0 & 21,0 & $22,0 \mathrm{~m}$ \\
\hline Chuta bola para frente. & 15,0 & 20,0 & 22,3 & $24,0 \mathrm{~m}$ \\
\hline Arremessa bola de cima para baixo. & 14,9 & 19,8 & 22,8 & $30,0 \mathrm{~m}$ \\
\hline Pula no lugar. & 20,5 & 22,3 & 30,0 & $36,0 \mathrm{~m}$ \\
\hline Pedala triciclo. & 21,0 & 23,9 & 33,0 & $36,0 \mathrm{~m}$ \\
\hline Equilibra-se sobre um pé 1". & 21,7 & 30,0 & 36,0 & $38,4 \mathrm{~m}$ \\
\hline Pulo amplo. & 2,0 & 2,8 & 3,0 & $3,2 \mathrm{a}$ \\
\hline Equilibra-se sobre um pé 5". & 2,6 & 3,2 & 3,9 & $4,3 \mathrm{a}$ \\
\hline Pula com um pé. & 3,0 & 3,4 & 4,0 & $4,9 \mathrm{a}$ \\
\hline Marcha calcanhar-ponta do pé. & 3,3 & 3,6 & 4,2 & $5,0 \mathrm{a}$ \\
\hline Pega bola que pula. & 3,5 & 3,9 & 4,9 & $5,5 \mathrm{a}$ \\
\hline Equilibra-se sobre um pé $10^{\prime \prime}$. & 3,0 & 4,5 & 5,0 & $5,9 \mathrm{a}$ \\
\hline Anda para trás, calcanhar-ponta do pé. & 3,9 & 4,7 & 5,6 & $6,3 \mathrm{a}$ \\
\hline
\end{tabular}

\section{B. Linguagem}

\begin{tabular}{|c|c|c|c|c|}
\hline Responde ao sino. & & & & $1,6 \mathrm{~m}$ \\
\hline Vocaliza sem chorar. & & & 1,3 & $1,8 \mathrm{~m}$ \\
\hline Sorri. & 1,4 & 2,0 & 2,6 & $3,3 \mathrm{~m}$ \\
\hline Grita. & 1,5 & 2,2 & 3,0 & $3,3 \mathrm{~m}$ \\
\hline Volta-se quando chamado. & 3,8 & 5,6 & 7,3 & $8,3 \mathrm{~m}$ \\
\hline "Papa", "Mama", não específicos. & 5,6 & 6,9 & 8,7 & $10,0 \mathrm{~m}$ \\
\hline Imita sons da fala. & 5,7 & 7,0 & 9,2 & $11,2 \mathrm{~m}$ \\
\hline "Papa", "Mama", específicos. & 9,2 & 10,1 & 11,9 & $13,3 \mathrm{~m}$ \\
\hline Três palavras, além de "mama", "papa". & 11,8 & 12,8 & 15,0 & $20,5 \mathrm{~m}$ \\
\hline Aponta para uma parte nomeada do corpo. & 14,0 & 17,0 & 21,0 & $23,0 \mathrm{~m}$ \\
\hline Combina 2 palavras diferentes. & 14,0 & 19,6 & 22,0 & $28,0 \mathrm{~m}$ \\
\hline Nomeia uma figura. & 15,9 & 20,3 & 25,0 & $30,0 \mathrm{~m}$ \\
\hline Compreende ordens; 2 de 3. & 14,8 & 19,8 & 22,0 & $32,0 \mathrm{~m}$ \\
\hline Usa o plural. & 20,0 & 28,0 & 33,0 & $38,5 \mathrm{~m}$ \\
\hline Dá o primeiro e último nome. & 2,0 & 2,7 & 3,2 & 3,8 a \\
\hline Compreende: "frio, cansaço, fome". & 2,6 & 2,9 & 3,5 & $4,1 \mathrm{a}$ \\
\hline Compreende 3 de 4 preposições. & 2,7 & 3,1 & 3,4 & $4,5 \mathrm{a}$ \\
\hline Reconhece 3 cores. & 2,7 & 3,0 & 3,7 & 4,9 a \\
\hline Analogias opostas; 2 de 3. & 2,9 & 3,2 & 4,8 & $5,3 \mathrm{a}$ \\
\hline Define 6 palavras de 9 . & 3,4 & 4,8 & 6,1 & $6,3 \mathrm{a}+$ \\
\hline Composição de materiais. & 3,9 & 4,9 & 5,7 & $6,3 \mathrm{a}+$ \\
\hline
\end{tabular}


Rev Med (São Paulo) 2003 jan.-dez.;82(1-4):22-33.

Tabela 8. Teste de "Screening" do Desenvolvimento de Denver (continuação)

\begin{tabular}{|c|c|c|c|c|}
\hline \multirow{2}{*}{$\begin{array}{l}\text { Item } \\
\text { C. Motor-adaptativo fino }\end{array}$} & \multicolumn{4}{|c|}{ Percentil } \\
\hline & $25 \%$ & $\mathbf{5 0 \%}$ & $75 \%$ & $90 \%$ \\
\hline Movimentos simétricos. & & & & $*$ \\
\hline Segue com o olhar até linha média. & & & 0,7 & $1,3 \mathrm{~m}$ \\
\hline Segue além da linha média. & & 1,3 & 1,9 & $2,5 \mathrm{~m}$ \\
\hline Une as mãos. & 1,3 & 2,2 & 3,0 & $3,7 \mathrm{~m}$ \\
\hline Segue por $180^{\circ}$. & 1,8 & 2,4 & 3,2 & $4,0 \mathrm{~m}$ \\
\hline Agarra o chocalho. & 2,5 & 3,3 & 3,9 & $4,2 \mathrm{~m}$ \\
\hline Olha objeto (bolinha). & 2,5 & 3,3 & 4,2 & $5,0 \mathrm{~m}$ \\
\hline Tenta pegar objeto. & 2,9 & 3,6 & 4,5 & $5,0 \mathrm{~m}$ \\
\hline Transfere o cubo de mão. & 4,7 & 5,6 & 6,6 & $7,5 \mathrm{~m}$ \\
\hline Sentado, olha um fio. & 4,8 & 5,6 & 6,9 & $7,5 \mathrm{~m}$ \\
\hline Sentado, pega 2 cubos. & 5,1 & 6,1 & 7,0 & $7,5 \mathrm{~m}$ \\
\hline Ajunta bolinhas. & 5,0 & 5,6 & 6,2 & $7,8 \mathrm{~m}$ \\
\hline Preensão usando polegar & 7,1 & 8,3 & 9,1 & $10,6 \mathrm{~m}$ \\
\hline Bate 2 cubos seguros nas mãos. & 7,0 & 8,4 & 9,8 & $12,3 \mathrm{~m}$ \\
\hline Preensão em pinça. & 9,4 & 10,7 & 12,3 & $14,7 \mathrm{~m}$ \\
\hline Torre com 2 cubos. & 12,1 & 14,1 & 17,0 & $20,0 \mathrm{~m}$ \\
\hline Derrama bolinha do recipiente, espontâneo & 12,7 & 13,4 & 16,4 & $24,0 \mathrm{~m}$ \\
\hline Rabisca espontaneamente. & 11,9 & 13,3 & 15,8 & $25,0 \mathrm{~m}$ \\
\hline Torre com 4 cubos. & 15,5 & 17,9 & 20,5 & $26,5 \mathrm{~m}$ \\
\hline Derrama bolinha do recipiente, demonstrado & 13,7 & 14,8 & 25,0 & $36,0 \mathrm{~m}$ \\
\hline Imita linha vertical com erro $30^{\circ}$. & 18,4 & 21,7 & 26,5 & $36,0 \mathrm{~m}$ \\
\hline Torre de 8 cubos. & 21,0 & 23,8 & 30,0 & $41,0 \mathrm{~m}$ \\
\hline Copia círculo. & 2,2 & 2,6 & 2,9 & $3,3 \mathrm{a}$ \\
\hline Imita ponte com cubos. & 2,3 & 2,7 & 3,1 & $3,4 \mathrm{a}$ \\
\hline Acerta linha mais longa; 3 de 3 . & 2,6 & 2,9 & 3,4 & $4,4 \mathrm{a}$ \\
\hline Copia + & 2,9 & 3,4 & 3,8 & $4,4 \mathrm{a}$ \\
\hline Desenha figura humana com 3 partes. & 3,3 & 4,0 & 4,7 & $5,2 \mathrm{a}$ \\
\hline Imita quadrado - demonstrativo. & 3,5 & 4,1 & 4,7 & $5,7 \mathrm{a}$ \\
\hline Copia quadrado. & 4,1 & 4,7 & 5,5 & 6,0 a \\
\hline Desenha figura humana com 6 partes. & 4,6 & 4,8 & 5,4 & 6,0 a \\
\hline
\end{tabular}

\section{Pessoal-social}

Olha para a face do examinador.

Sorri responsivamente.

Sorri espontaneamente.

Come biscoito com as mãos.

Procura brinquedos fora do alcance.

Brinca de esconder.

Resiste à retirada de brinquedos.

Inicialmente tímido com estranhos.

Brinca de bater sobre objeto.

Indica desejos sem chorar.

Joga bola com o examinador.

Bebe do copo.

Imita serviços domésticos.

Remove roupas do corpo.

Usa a colher, derramando pouco.

Ajuda em casa - tarefas simples.

Põe os sapatos, sem laço.

Lava e enxuga as mãos.

Brinca com jogos interativos.

Veste-se, com supervisão.

Consegue se abotoar.

Separa-se da mãe com facilidade.

Veste-se sem supervisão. 
A performance de uma dada criança no teste é classificada como: (1) normal, se a mesma não apresenta nenhum atraso no desenvolvimento nos diversos itens do teste, isto é, ela não falha em itens que foram superados por $90 \%$ das crianças controles; (2) duvidoso, se a performance foi questionável, significando que a criança apresenta um atraso em um item, ou não passou em pelo menos um item em cada setor da sua idade cronológica, que foi superado por $90 \%$ das crianças controle; (3) anormal, ou atraso importante, é atribuído à criança que falha em dois ou mais itens em qualquer setor do desenvolvimento.

Quando a criança falha em apenas um ou dois itens em todo o teste, o ideal é reexaminar a criança numa próxima oportunidade (em dois ou três meses) e comparar o resultado das duas avaliações. Se o atraso persistir, a causa deve ser investigada através de encaminhamento para especialista. Outro aspecto importante são as circunstâncias presentes durante o exame. Se a criança apresenta uma intercorrência médica (p. ex.: quadro infeccioso), ou está particularmente irritadiça e chorosa no momento do exame, a validade do mesmo pode ser comprometida sendo mais prudente adiálo para uma data mais oportuna.

O teste é composto de itens divididos por setores de desenvolvimento: motor grosseiro, linguagem, motoradaptativo fino e pessoal-social, e foi modificado e ampliado após a sua edição inicial. Os diversos itens estão relacionados na Tabela 8 .

Gherpelli JLD. Neurological evaluation and follow-up of the newborn infant. Rev Med (São Paulo) 2003 jan.-dez.;82(1-4):22-33.

\begin{abstract}
The author describes the clinical neurological evaluation of the newborn infant at term and pre-term, with special remarks on the most frequently used techniques in clinical practice, and the neurological syndromes observed in the neonatal period. The developmental patterns found in normal children in the first years of life are described according to the major areas of development: motor, language, motor coordination and adaptative, along with the tests most frequently used for the evaluation of pre-school children.
\end{abstract}

KEYWORDS: Psychomotor performance. Child development. Neurologia examination/methods. Infant, newborn. Infant, premature.

\section{REFERÊNCIAS}

1. Frankenburg WK, Doods JB. The Denver developmental screening test. J Pediatr 1967;71:181-91.

2. Gherpelli JLD. Desenvolvimento do sistema nervoso central. In: Zugaib M, Kanas M, editores. Fisiologia fetal aplicada. São Paulo: Roca; 1986. p.169-85.

3. Gherpelli JLD, Casagrande MS, Kfuri JM, Costa HPF. Síndrome da hiperexcitabilidade no período neonatal. Arq Neuropsiquiatr 1993;51:46-50.

4. Knobloch H, Pasamanick B. Gesell and Amatruda's developmental diagnosis. New York: Harper \& Row; 1974.

5. Prechtl HFR. The behavioural states of the newborn infant. Brain Res 1974;76:185-201.

6. Prechtl HFR, Beintema D. The neurological examination of the full-term newborn. London: William Heinemann Med B; 1964. (Clinical development medicine, 12)

7. Saint-Anne Dargassies S. Le développement neurologique du nouveau-né à term et prématuré. Paris: Masson; 1974.

8. Volpe JJ. Neurology of the newborn. Philadelphia: WB Saunders; 1995. 